\title{
Research on the Reform and Practice of "Three Oriented" Training Mode for International Nursing Specialty
}

\author{
Liqun Yang, Hongmin Liu, Meiling Tang, Qiang Li \\ Qiqihar Medical University, Qiqihar, Heilongjiang, 161006
}

Keywords: Three oriented; Internationalization; Personnel training mode; Nursing specialty

\begin{abstract}
Objective: Discussion on the construction and research of "three oriented" international nursing talents training mode. Method: Based on the "three oriented" personnel training model and the international training standards for nursing talents, this paper analyzes and constructs the training plan of nursing talents, reforms the teaching methods, and constructs the teaching evaluation system. Result: Under the model of "three oriented" international nursing talents training, the teaching of nursing specialty is based on humanistic quality, professional quality and physical and psychological quality, carrying out a comprehensive reform. The overall improvement of the quality of teachers, teaching quality has been guaranteed, the satisfaction level of graduates employing $90 \%$ or more, and the employment rate has increased year by year. Conclusion: This study provides a theoretical basis for the construction and research of the international nursing education system under the "three oriented" personnel training mode, and provides practical experience.
\end{abstract}

\section{Introduction}

Internationalization of higher education has created favorable conditions for the international exchange of nursing talents. Research and discussion on training models of higher nursing personnel adapted to the international trend have become an important issue facing the reform of higher nursing education in China [1,2]. In recent years, our school has carried out research and practice on the training mode of international nursing personnel based on the "three directions", reforming the curriculum system, innovating teaching methods and nursing practice teaching system, establishing a comprehensive quality training standard and assessment system, and training students to " Patient-centered "concept of care, so that the students nursing occupational emotion, nursing professional ethics, nursing professionalism, nursing professional quality and ability have been fully developed.

\section{2. "Three-oriented" personnel training mode}

As a province-specific applied medical undergraduate college, our school insists on carrying out the reform and innovation of applied medical personnel training system and actively develops the unique nursing science which integrates "three-oriented" personnel training mode and internationalized nursing education mode Professional training mode.

Three-oriented personnel training mode consists of three parts [3-5]: First, the occupation of emotional oriented humanistic education; second is based on the ability to practice professional-oriented quality-oriented training; third is based on social adaptation-oriented physical and mental quality Develop. Adhere to the "four unifications" in educational ideology: the unification of basic knowledge and post competency, the unification of medical literacy and humanistic literacy, the unification of all-round development and personality development, and the unification of scientific spirit and professionalism. The concept of education to achieve "three changes": from teacher-centered to student-centered; teacher knowledge transfer into ability training; from passive student learning to active learning. Fully respect the laws of education, the future development of students as the goal, pay attention to critical thinking, innovative thinking, clinical nursing thinking and nursing professional quality training. Construct a three-oriented training model 
aiming at the future development of students, and strive to train applied nursing professionals with good professional qualifications, initial clinical ability, lifelong learning ability and social adaptability.

\section{3. "Three-oriented" international nursing professional training program development principles}

Based on the relevant requirements of "Nursing Undergraduate Professional Code" and "Undergraduate Medical Education Standards - Nursing Specialty", combined with the international model of nursing education, to establish a "three-oriented" Nursing Talents Training Program that is suitable for the development of health care business system.

Follow the basic laws of education and teaching, adhere to the equal emphasis on knowledge, ability and quality education, focus on improving students humanities and moral qualities, and strengthen students' ability of independent study, practical ability, innovative ability and foreign-related ability.

Scientifically designed curricular programs, focusing on curriculum integration and subject integration, promote "three early education", that is, early contact with society, early exposure to clinical and early exposure to scientific research, to achieve the theoretical teaching and practical teaching, in-class education and extra-curricular education.

To reform the curriculum system and establish a comprehensive quality training standard and assessment system to bridge the gap between Chinese and foreign nursing concepts and contents as well as training in medical and public foreign languages based on strengthening domestic nursing education.

\section{4. "Three-oriented" curriculum structure of international nursing professional curriculum}

In accordance with the "three-oriented" personnel training model requirements, based on the national nursing professional education standards, all-round development of students as the goal, optimize the integration of curriculum system. Adhere to the "five combinations", that is, the theory and practice, class and extracurricular, commonalities and individualities, humanities and science, the combination of the school and the outside of the school to break the traditional three-stage curriculum set pattern in each teaching module in the compulsory courses, elective courses, extra-curricular practice links to form a complete curriculum system.

Including ideological and political education, nursing humanities education and nursing career development education three curriculum groups. Through the system of humanities, social sciences and career development education, make students become caring, patient, compassionate, noble medical ethics, with good professionalism nurses.

Including basic medical knowledge, public health knowledge, Nursing knowledge and practical skills training, scientific research methods and graduate production internship six courses. Through the system of professional knowledge learning and comprehensive skills training, so that students have a solid basic theory of nursing science and professional knowledge, self-learning ability and practical ability, innovative awareness and good professional qualities of nursing personnel.

Including military, physical education and life, psychological education, two course groups. Cultivate nurse professionals who respect life, health, good mental quality and social adaptability.

Increase the proportion of public English teaching, public English intensive reading, reading, listening, speaking, writing and other courses, while increasing professional English and nursing oral English courses, nursing oral training for common clinical scenarios [6]. The courses include: Introduction to Nursing in Foreign Countries, Introduction to English-speaking Countries, Reading and Exchange of Nursing English Literature, Essentials of CGFNS Examinations, and Training and Interpretation of IELTS and RN Test Questions [7,8]. Increase the proportion of bilingual teaching in nursing major and strengthen training for students' weak points in English learning.

Emphasis on nursing practice teaching reform, nursing practice teaching is an important part of nursing teaching [9]. Construct a practical teaching system composed of early contact with clinical 
practice, course experiment teaching, inter-class traineeship, clinical nursing comprehensive skill training, graduation practice (including spirit and community) and social practice. The curriculum plans shall clearly define the proportion of each teaching link. In order to help students get in touch with the clinic early, they have set up "Nursing Professional Experience Classes". The first semester of the freshman year experiences clinical nursing. Students in the Experimental Teaching Center for Nursing to carry out curriculum experimental teaching and clinical nursing comprehensive skills training; to affiliated hospitals, clinical teaching base, international hospitals and community health centers for early exposure to clinical, internship and graduation internship; into the hospital, community, nursing home to carry out social practice.

\section{5. "Three-oriented" international nursing professional personnel training mode implementation guarantee}

According to the modern education concept, establishing the education idea of "everything for student development", the teaching process changes from "teaching-centered" to "student-centered", focusing on improving students 'learning efficiency and learning effectiveness, developing students' independent study and communication Exchange, analyze and solve problems, teamwork and other aspects of the capacity $[10,11]$. Through the top-level design, the connotation of indicators suitable for nurses in applied nursing is established, emphasizing the cultivation of students' practicing ability, professional ethics and physical and mental qualities, creating a modular teaching system, intensifying the reform of the curriculum and advancing the advanced teaching methods and assessment methods Application, innovation education and teaching management and evaluation system, create a positive environment for education and teaching, improve the application of medical personnel training.

Select the outstanding management cadres and key teachers to form a research team to conduct an in-depth study of personnel training requirements, personnel training programs, curriculum system reform, curriculum, teaching methods, teaching evaluation, personnel training quality evaluation.

Create three levels of indicators under six secondary indicator systems based on humane professional attitude, altruistic values, humanistic communication art, responsible legal awareness, vision-based teamwork and ethical-based behavior.

To create skills based on basic knowledge and application of clinical nursing skills, operational skills and nursing practice ability, disease prevention and health promotion ability, critical thinking and nursing research ability, clinical nursing thinking and nursing evidence-based integration ability, nursing information technology and patient management ability and lifelong learning and professional ability to enhance seven secondary indicators under the three indicators.

To create a three-level indicator based on six second-level index system based on self-sports awareness and habits, knowledge and skills of sports and fitness, self-reflection and personality perfection, psychological adjustment and interpersonal coordination.

According to the needs of teaching, course leaders should adopt different teaching methods and strengthen the combination of theoretical teaching and practical teaching, professional education and professional ability training. Adhere to the principle of "students are the main body of study", fully mobilize the enthusiasm of teachers in teaching reform and promote the reform and study of teaching methods with "taking students as the center" and "promoting students' independent study" as the main content. For example, PBL, case-based teaching, flip classroom, experiential teaching, situational teaching and other teaching methods are used in the teaching of Nursing professional courses to cultivate the ability of students to find out problems, analyze problems and solve problems, and develop students' autonomous learning ability and team Consciousness at the same time, pay attention to the development of critical thinking, concerned about the development of humanistic care and communication and collaboration.

In order to ensure the implementation of the teaching plan and the normal operation of all aspects of teaching, according to "Operation Regulations of Teaching Quality Assurance System in Qiqihar Medical College" and "Teaching Quality Assessment Scheme for Teachers in Qiqihar 
Medical College", the "Operational Rules for Teaching Quality Assurance System of Nursing College", The implementation of "school - nursing college - teaching and research" three teaching quality management. The school set up a Teaching Steering Committee, the College of Nursing set up a Teaching Committee and a Teaching Steering Committee. Through educational supervision and assessment, online evaluation of students and symposiums for teachers and students, various educational evaluations have been formed involving leaders, teachers, students and administrators system. According to "Qiqihar Medical College teacher teaching quality assessment program", "nursing college leadership attendance system", "nursing college teaching inspection system", "Nursing College Curriculum Management Regulations" and other standards, the teaching of all aspects of quality evaluation.

The research and practice of "three directions" international nursing professionals training mode promoted the nursing education in our school and international exchanges, promoted the reform of higher nursing education in our university, the comprehensive quality of students was continuously improved, and the employment of graduates in the past three years The results of the survey showed that the employers 'satisfaction with graduates' love of their jobs, nursing occupational attitudes, nursing occupational feelings, practicing ability, teamwork and communication skills all exceeded $90 \%$, and that of employers of international graduates reached $95 \%$, The nursing profession employment rate reached $100 \%$ [12], the international employment rate is also increasing year by year. Under the guideline of "three-oriented" personnel training mode, our hospital successfully passed the nursing professional certification of the Ministry of Education in 2015. The expert group of the Ministry of Education has taken great care of the college from the aspects of teaching staff construction, curriculum integration and education and teaching research The achievements of the school have been affirmed. Our hospital will continue to explore the related research of "three orientations" international nursing professionals training mode, increase the construction of the course, improve the personnel training system, and continuously improve the teaching quality.

\section{Acknowledgement}

Fund Project: Heilongjiang Philosophy and Social Sciences Research Project (15EDB05)

\section{References}

[1] Gao Jing, Chen Peiyi. Reflections on Cross-cultural Nursing Education in Higher Nursing Institutions in the Context of Internationalization [J]. Journal of General Nursing, 2015,13 (17): 1606-1607.

[2] Liu Guijuan, Guo Lingling, Xu Jinmei. The training strategy of internationalized nursing core competence [J]. Nursing Practice and Research, 2014,11 (12): 116-117.

[3] Liu Jicheng, Zhang Xiaojie, Yun Changhai, etc. Exploration and practice of the three-oriented training model reform aimed at the future development of medical students [J]. China Higher Medical Education, 2014, (4): 1-2.

[4] Cui Guangcheng, Zhang Xiaojie, Bai Li, etc. Occupational emotion-oriented reform of the medical humanities quality and practice [J] Chinese Higher Medical Education, 2014, (4): 3-4.

[5] Zhang Xiaojie, Yun Changhai, Luo Qingdong, etc. Professional competence-oriented professional quality training research and practice [J]. China Higher Medical Education, 2014, (4): 5-6.

[6] Gabr H, Mohamed N. Effect of problem-based learning on undergraduate nursing students enrolled in nursing administration course [J]. Int J Academic Res, 2011, 3 (1): 154-162.

[7] Garrett BM. Changing the game: some thoughts on future healthcare demands, technology, nursing and inter professional education [J]. Nurse Educ Pract, 2012, 12 (4): 179-181.

[8] Kelleher S. Perceived benefits of study abroad programs for nursing students: an intergrative 
review [J]. J Nurs Educ Dec, 2013, 52 (12): 690-695.

[9] O'Connor J, Carr A. Problem-based learning in Guyana: A nursing education experiment [J]. International nursing review, 2012, 59 (3): 376-379.

[10] Zhang Chunqing, Liu Zhongjin, Han Junyan, etc. Study on strategies for training clinical practice ability of medical students based on "three directions" [J]. Zhonghua Yi Xue Tan Za Zhi, 2016,15 (11): 1094-1097.

[11] Reid-Searl K, Dwyer T, Moxham L, et al. Rediscovering the essence of nursing: exporing the impact of in clinnical experience in Thailand for undergraduate nursing students from Australia [J]. Nurse Educ Today, 2011, 31 8): 892-897.

[12] Yang Liqun, Li Qiang, Li Meiqian, etc. "Nursing professional quality and ability" school-based curriculum development and construction [J]. Chinese Journal of Nursing, 2015,21 (12): 1438-1440. 